\title{
Is it time to move away from short-acting beta-agonists in asthma management?
}

\author{
Matthew J. Martin and Tim W. Harrison
}

Affiliation: The Asthma Centre, Nottingham NIHR Respiratory BRC, University of Nottingham, Nottingham City Hospital, Nottingham, UK.

Correspondence: Matthew Martin, University of Nottingham, Respiratory Research Unit, Nottingham City Hospital, Hucknall Road, Nottingham, NG5 1PB, UK. E-mail: matthew.martinanottingham.ac.uk

@ERSpublications

Frequent SABA use is associated with adverse asthma outcomes and evidence suggests replacing SABA with fast-acting LABA/ICS as reliever therapy reduces asthma exacerbation risk. We believe the time has come to move away from SABAs in asthma management. http://ow.ly/87UJ30nVGNc

Cite this article as: Martin MJ, Harrison TW. Is it time to move away from short-acting beta-agonists in asthma management? Eur Respir J 2019; 53: 1802223 [https://doi.org/10.1183/13993003.02223-2018].

Asthma is a common chronic inflammatory disease of the airways, which continues to cause considerable morbidity and unnecessary mortality across the world $[1,2]$. The recognition that even mild asthma is associated with airway inflammation led to the early and widespread use of inhaled corticosteroids (ICS) from the 1970s onwards [3, 4], transforming asthma care by significantly reducing severe exacerbations and asthma deaths. However, the persistently high levels of poor asthma control and ongoing asthma deaths in the 21st century are a growing concern $[5,6]$ and we believe the widespread use and overuse of short-acting beta-agonist (SABA) inhalers are a major part of the problem.

SABAs are highly effective bronchodilators which quickly relieve the symptoms associated with bronchoconstriction, the hallmark of asthma. Nevertheless, as highlighted in previous reviews [7], they have a chequered history in terms of safety. Epidemics of asthma deaths in the 1980s were linked to the use of high doses of potent non-selective SABAs [8] and it has been demonstrated that more frequent SABA use is associated with higher risk of future exacerbation [9], hospital admission [10] and increased levels of airway inflammation [11, 12]. SEARs et al. [13] and SuISSA et al. [14] demonstrated a link between increased SABA use and mortality from asthma leading to recommendations for regular anti-inflammatory medication and as-required SABA for all but the mildest cases of intermittent asthma.

Evidence suggests that SABAs continue to be responsible for high levels of poorly controlled asthma and even asthma deaths, not necessarily because of direct detrimental effects but because they are used preferentially by patients in place of regular ICS or long-acting beta-agonist (LABA)/ICS and in place of additional ICS when asthma control starts to deteriorate $[15,16]$. Increased SABA use at the time of worsening asthma symptoms leads to symptom relief but does nothing to suppress the increased burden of airway inflammation, therefore masking the underlying problem. Factors associated with asthma death include: 1) lack of a recent asthma review (where underuse of ICS could be identified), 2) lack of seeking medical help (when oral corticosteroid treatment could have been initiated), 3) lack of written self-management plans (which may encourage regular ICS use and increased ICS treatment when asthma control is deteriorating), 4) overuse of SABAs and 5) underuse of ICS [5].

The 2016 revision of the British Thoracic Society (BTS)/Scottish Intercollegiate Guidelines Network (SIGN) guidelines appear to have taken a step in the right direction by removing step 1 (SABA 
monotherapy) and proceeding straight to low dose ICS in suspected or confirmed asthma in their summary figure. However, the figure still recommends SABA monotherapy for those with "infrequent, short-lived wheeze" and guidance in the text recommends ICS for asthma patients using inhaled SABA three times a week or more, in patients with symptoms three times a week or more, or in patients waking one night a week or more [17]. Low dose ICS are highly effective even in very mild asthma [18], but unfortunately multiple surveys have shown that ICS adherence is poor, particularly in this group of patients, presumably due to their low symptom burden [15].

So is there an alternative? PAPI et al. [19] demonstrated in 2007 that "as required" use of a combined beclomethasone/salbutamol inhaler is more effective than as required salbutamol and as effective as twice daily beclomethasone and SABA. More recently, the first of the two SYGMA studies confirmed that a quick-acting LABA/ICS combination inhaler provides superior symptom control and a reduction in exacerbation rate compared to SABA when used as required [20]. In the second SYGMA study [21] the benefits of as required LABA/ICS compared with regular low dose ICS were not as clear cut, with a similar risk of severe exacerbations observed for these two treatment strategies, but a statistically, although not clinically significant, difference in ACQ5 in favour of regular ICS treatment. However, being a regulatory, double-blind, placebo-controlled study adherence rates to maintenance treatment $(\sim 60 \%)$ were much higher than those generally observed in real life ( 35\%) [22] so the results of real-life studies comparing LABA/ICS versus low dose ICS $[23,24]$ are awaited with interest.

For patients with moderate persistent asthma treatment with regular ICS with or without a LABA is now the treatment of choice and is highly effective if used regularly. Unfortunately, once again, adherence with LABA/ICS combinations is poor despite many years of asthma education. A real-life study with the once daily combination inhaler Relvar and as required SABA suggested improved asthma control over standard asthma management with a similar rate of severe exacerbations, although the additional improvement in asthma control test score seen in the treatment group when compared to the standard care group did not exceed the minimal clinically important difference [25]. However, a major problem with any strategy that includes a SABA is how to deal with deteriorating asthma control. When experiencing worsening symptoms, patients once again rely on their SABA, which provides symptom relief but no anti-inflammatory effects and may aggravate the situation if taken regularly for symptoms with no background ICS due to poor adherence $[13,14]$. Self-management plans are therefore recommended to encourage patients to increase their ICS dose to regain control and abort an exacerbation. Although we have recently shown that a four-fold increase in ICS is effective in this setting [26], it is less easily achieved in the majority of patients taking a LABA/ICS combination twice daily as the safety of increasing all types of LABA four-fold is unknown.

In patients taking regular ICS with or without LABA, replacing SABA with fast-acting LABA/ICS combinations makes it possible to avoid SABA overuse and ensures that each time a patient takes an inhaler for symptom relief they receive extra ICS rather than extra SABA. Many studies have shown the benefit of this approach, and a recent meta-analysis concluded that replacing SABA with fast-acting LABA/ICS reliever therapy results in a one-third reduction in risk of severe exacerbations and a $25 \%$ reduction in risk when compared with double the baseline maintenance ICS/LABA and SABA treatment [27]. It should be noted that most of the studies included in this meta-analysis recruited patients with at least one exacerbation in the previous year or poor asthma control, i.e. more "exacerbation prone" patients. In contrast, data from several "real-life" open-label studies comparing LABA/ICS reliever therapy and conventional best practice with no inclusion criteria related to prior exacerbations or control have shown little or no significant difference in exacerbation rate, although these have demonstrated that LABA/ICS reliever therapy results in the same or improved asthma control with a significantly lower daily ICS dose $[28,29]$. The above does not seem to be reflected in the treatment algorithm in the most recent BTS/SIGN guidelines which recommends SABA reliever therapy in all patients and does not mention LABA/ICS as reliever therapy [17].

These problems are magnified many times in some low- and middle-income countries which have the highest worldwide asthma mortality rates [30]. In these countries, millions of patients with all severities of asthma are only able or willing to afford SABA treatment, even though ICS are available. An inhaler containing a SABA and ICS, provided it was no more expensive than SABA treatment, could therefore lead to a dramatic change in asthma mortality in the developing world.

There are, however, some practical concerns that need to be addressed and areas in which further evidence is required before a recommendation to end unopposed SABA use could easily be implemented. Firstly, the evidence supporting formoterol/ICS as a reliever therapy is much greater than for SABA/ICS, which is not available in most markets and is only approved for regular use in those that it is. Also, currently there are no data demonstrating the efficacy and safety of combining formoterol/ICS with maintenance treatment that does not contain formoterol. Therefore, at present all patients requiring combination 
therapy would have to be treated with a formoterol containing combination licensed for both maintenance and relief, which would not be possible in countries such as the USA, where ICS/formoterol combinations are approved as maintenance therapy only. Secondly, the role of ICS/beta-agonist therapy in situations for which SABA monotherapy is currently used, such as acute severe asthma, needs to be evaluated.

In conclusion, we believe it is time to move asthma management away from SABAs for patients with confirmed asthma but further data is urgently required to make this a practical ambition. At best, SABAs mask ongoing airway inflammation by providing symptom relief and adversely affect adherence with anti-inflammatory treatment and, at worst, they potentiate inflammation when taken regularly for symptom control in patients who have stopped their ICS treatment $[13,14]$. In our opinion, as required beta-agonists should always be combined with additional corticosteroid.

Author contributions: T.W. Harrison had the original idea for the manuscript. M.J. Martin and T.W. Harrison wrote the manuscript.

Conflict of interest: M.J. Martin has nothing to disclose. T.W. Harrison reports personal fees and non-financial support from AstraZeneca, personal fees from Vectura, and non-financial support from Teva and NAPP, outside the submitted work.

\section{References}

1 Soriano JB, Abajobir AA, Abate KH, et al. Global, regional, and national deaths, prevalence, disability-adjusted life years, and years lived with disability for chronic obstructive pulmonary disease and asthma, 1990-2015: a systematic analysis for the Global Burden of Disease Study 2015. Lancet Respir Med 2017; 5: 691-706.

2 Ebmeier S, Thayabaran D, Braithwaite I, et al. Trends in international asthma mortality: analysis of data from the WHO Mortality Database from 46 countries (1993-2012). Lancet 2017; 390: 935-945.

3 Brown HM, Storey G, George WHS. Beclomethasone dipropionate: a new steroid aerosol for the treatment of allergic asthma. Br Med J 1972; 1: 585-590.

4 Inhaled corticosteroids compared with oral prednisone in patients starting long-term corticosteroid therapy for asthma. A controlled trial by the British Thoracic and Tuberculosis Association. Lancet 1975; 2: 469-473.

5 Levy ML. The national review of asthma deaths: what did we learn and what needs to change? Breathe (Sheff) 2015; 11: 14-24.

6 Pavord ID, Mathieson N, Scowcroft A, et al. The impact of poor asthma control among asthma patients treated with inhaled corticosteroids plus long-acting $\beta 2$-agonists in the United Kingdom: a cross-sectional analysis. NPJ Prim Care Respir Med 2017; 27: 17.

7 Donohue JF. Safety and efficacy of beta agonists. Respir Care 2008; 53: 618-622.

8 Pearce N, Hensley MJ. Epidemiologic studies of beta agonists and asthma deaths. Epidemiol Rev 1998; 20: 173-186.

9 Stanford RH, Shah MB, D'Souza AO, et al. Short-acting beta-agonist use and its ability to predict future asthma-related outcomes. Ann Allergy Asthma Immunol 2012; 109: 403-407.

10 Gonem S, Cumella A, Richardson M. Asthma admission rates and patterns of salbutamol and inhaled corticosteroid prescribing in England from 2013 to 2017. Thorax 2019; in press [https://doi.org/thoraxinl-2018-212723].

11 Swystun VA, Gordon JR, Davis EB, et al. Mast cell tryptase release and asthmatic responses to allergen increase with regular use of salbutamol. J Allergy Clin Immunol 2000; 106: 57-64.

12 Aldridge RE, Hancox RJ, Cowant JO, et al. Eosinophils and eosinophilic cationic protein in induced sputum and blood: effects of budesonide and terbutaline treatment. Ann Allergy Asthma Immunol 2002; 89: 492-497.

13 Sears MR, Taylor DR, Print CG, et al. Regular inhaled beta-agonist treatment in bronchial asthma. Lancet 1990; 336: $1391-1396$

14 Suissa S, Blais L, Ernst P. Patterns of increasing beta-agonist use and the risk of fatal or near-fatal asthma. Eur Respir J 1994; 7: 1602-1609.

15 Partridge MR, van der Molen T, Myrseth SE, et al. Attitudes and actions of asthma patients on regular maintenance therapy: the INSPIRE study. BMC Pulm Med 2006; 6: 13.

16 Patel M, Pilcher J, Hancox RJ, et al. The use of beta2-agonist therapy before hospital attendance for severe asthma exacerbations: a post-hoc analysis. NPJ Prim Care Respir Med 2015; 25: 14099.

17 British Thoracic Society, Scottish Intercollegiate Guidelines Network. British Guideline for the Management of Asthma: a National clinical Guideline. London/Edinburgh, BTS/SIGN, 2016. Available from: https://www. brit-thoracic.org.uk/standards-of-care/guidelines/btssign-british-guideline-on-the-management-of-asthma

18 Reddel HK, Busse WW, Pedersen S, et al. Should recommendations about starting inhaled corticosteroid treatment for mild asthma be based on symptom frequency: a post-hoc efficacy analysis of the START study. Lancet 2017; 389: 157-166.

19 Papi A, Canonica GW, Maestrelli P, et al. Rescue use of beclomethasone and albuterol in a single inhaler for mild asthma. N Engl J Med 2007; 356: 2040-2052.

20 O’Byrne PM, FitzGerald JM, Bateman ED, et al. Inhaled combined budesonide-formoterol as needed in mild asthma. N Engl J Med 2018; 378: 1865-1876.

21 Bateman ED, Reddel HK, O'Byrne PM, et al. As-needed budesonide-formoterol versus maintenance budesonide in mild asthma. N Engl J Med 2018; 378: 1877-1887.

22 Foster JM, Usherwood T, Smith L, et al. Inhaler reminders improve adherence with controller treatment in primary care patients with asthma. J Allergy Clin Immunol 2014; 134: 1260-1268.

23 Beasley R, Pavord I, Papi A, et al. Description of a randomised controlled trial of inhaled corticosteroid/fast-onset LABA reliever therapy in mild asthma. Eur Respir J 2016; 47: 981-984.

24 Fingleton J, Hardy J, Baggott C, et al. Description of the protocol for the PRACTICAL study: a randomised controlled trial of the efficacy and safety of ICS/LABA reliever therapy in asthma. BMJ Open Respir Res 2017; 4: e000217. 
25 Woodcock A, Vestbo J, Bakerly ND, et al. Effectiveness of fluticasone furoate plus vilanterol on asthma control in clinical practice: an open-label, parallel group, randomised controlled trial. Lancet 2017; 390: 2247-2255.

26 McKeever T, Mortimer K, Wilson A, et al. Quadrupling inhaled glucocorticoid dose to abort asthma exacerbations. N Engl J Med 2018; 378: 902-910.

27 Sobieraj DM, Weeda ER, Nguyen E, et al. Association of inhaled corticosteroids and long-acting $\beta$-agonists as controller and quick relief therapy with exacerbations and symptom control in persistent asthma: a systematic review and meta-analysis. JAMA 2018; 319: 1485-1496.

28 Demoly P, Louis R, Soes-Petersen U, et al. Budesonide/formoterol maintenance and reliever therapy versus conventional best practice. Respir Med 2009; 103: 1623-1632.

29 Soes-Petersen U, Kava T, Dahle R, et al. Budesonide/formoterol maintenance and reliever therapy versus conventional best standard treatment in asthma in an attempted 'real life' setting. Clin Respir J 2011; 5: 173-182.

30 Global Asthma Network. The Global Asthma Report 2018. Auckland, Global Asthma Network, 2018. Available from: http://globalasthmareport.org/Global\%20Asthma\%20Report\%202018.pdf 